\title{
Antioxidative Properties of Irradiated Chitosan/Vitamin C Nanoparticles and their Use as Food Additive for Lipid Storage
}

\author{
A. M. Elbarbary*\#, N. M. El-Sawy and E. A. Hegazy \\ Radiation Research of Polymer Chemistry, National Centre for \\ Radiation Research and Technology (NCRRT), P. O. Box: 29 \\ Nasr City, Cairo, Egypt. "E-mail; amelbarbary@Yahoo.com.
}

\begin{abstract}
CHITOSAN (CS) antioxidant activity improvement was achieved by decreasing their molecular-weight (MW) by $\gamma$-rays followed by incorporation with vitamin $\mathrm{C}(\mathrm{VC})$ to prepare chitosan/vitamin $\mathrm{C}$ (CSVC) complex in the range of nanoparticles. Transmittance Electron Microscopy (TEM) of CSVC complex showed mean diameters ranged from 23.2 to $82 \mathrm{~nm}$.

The antioxidant activities of CSVC complexes were examined using scavenging effect on 2,2-diphenyl-1picrylhydrazyl (DPPH) radicals and reducing power measurements. CSVC complexes have a synergistic effect on increasing the antioxidant properties rather than their individual effects. The effect of CSVC complexes on lipid peroxidation of meat during 21 days of refrigerated storage was investigated using thiobarbituric acid reactive substance (TBARS) assay.

Treatment of meat with CSVC complex delayed lipid peroxiation about $75 \%$ after 7 days of storage as a result the decrease in TBARS values. The results demonstrate promising use of CSVC complex as antioxidants and food additive for lipid storage.

Keywords: Chitosan, radiation, vitamin C, antioxidant, meat storage, lipid.
\end{abstract}

One of the most important factors that influence the quality and acceptance of meat and poultry during refrigerated or frozen storage is lipid oxidation. The oxidation of lipids leads to rancidity, change in food quality such as colour, aroma, flavour, texture and even the nutritive value of the food. Controlling and monitoring of lipid oxidation during meat processing or storage are important due to the increase demand for precooked convenient meat products for home, fast food and institutional uses (Nissen et al., 2004). 
In order to protect lipids, avoid deterioration of appearance, and microbial growth in meat product manufacturers, several food additives with antimicrobial and antioxidant properties were used (Georgantelis et al., 2007, Li et al., 2013 and Suman et al., 2011). The use of food additive in food industry to preserve flavour or enhance its taste and appearance improves food processing, preservation, quality and safety, as well as increased production, cost-effectiveness and sustainability. Nowadays, there is an increased demand for healthier food products without chemical preservatives, resulting in a need to avoid the use of synthetic additives. This has favoured the use of natural additives or alternative methods to extend shelf life and/or improve safety. CS is one of these alternatives. It has been used in food products as preservative in fresh pork sausages (Soultos et al., 2008), fresh pork burgers (Sayas-Barberá et al., 2011), preservative for meat and meat products (Suman et al., 2011), frozen beef burgers (Georgantelis et al., 2007) and edible coatings for fruit and vegetables (Ma et al., 2013) due to its antibacterial and antifungal activities (Rao et al., 2005).

CS has attracted attention as a biomedical material, owing to its unique biological activities including antitumor activities (Suzuki, et al., 1986), immune-stimulating effects (Jeon and Kim, 2001), antimicrobial effects (Park et al., 2004), antioxidant activity (Abd El-Rehim et al., 2012, Sun et al., 2011, and Ying et al., 2011), wound healing effects (Porporatto et al., 2003), free radical scavenging activities (Anraku et al., 2008) and chelating activity that selectively binds protein and metals (Yen et al., 2008). The applications of CS in food industry and medicine are limited because of its high MW resulting in its low solubility in aqueous media (Ilyina et al., 2000). It is important to improve the water solubility of CS to expand its usefulness in food industry. In recent years, radiation induced degradation of CS to obtain low MW and to become more interesting for development of many successful applications in agriculture, health care, food, and environmental protection.

Antioxidants are an important group of food additives as health protecting factors for prevention of oxidative damage and extend shelf life of foods. Recently, the antioxidant activity of CS and its derivatives has attracted attention (Park at al., 2004, Sun et al., 2011, and Ying et al., 2011). Ascorbic acid is a naturally occurring organic compound with antioxidant properties and Egypt. J. Rad. Sci. Applic., Vol. 27, No. 1-2 (2014) 
can be used as antioxidant and food additives due to the presence of the enediol moiety. The biochemical functions of $\mathrm{VC}$ such as scavenger reactive oxygen species, antivirus and antitumor are of increasing interests.

In this study, antioxidant activity of CS was enhanced by subjecting CS to $\gamma$-rays at different doses to prepare low MW followed by chemical treatment with VC to obtain CSVC complexes and their effectiveness in reducing the lipid peroxidation during refrigerated storage of meat will be examined.

\section{Materials and methods}

\section{Materials}

CS, Aldrich, high MW 1.9x10 $10^{6}$ Da, DD> 85\%. VC, El-Nasr Company for chemicals, Egypt. DPPH was purchased from Sigma Alderch, USA. Ferric chloride and ferrous chloride were supplied from BDH. Potassium ferricyanide was supplied from Riedel laboratory reagents. Trichloroacetic acid (TCA) and thiobarbituric acid (TBA) were supplied from SUVCHEM laboratory chemicals. Other reagents and solvents were of analytical grade.

\section{Characterization and analysis}

The absorbance was measured by a UV-Vis spectrophotometer JASCO V560 Japan, in the range of $190-900 \mathrm{~nm}$. The transmittance (\%) was measured using infra-red spectrophotometer FT-IR 6300 JASCO, Japan. The MW was determined by Gel permeation chromatography (GPC) 1100 Agilent instrument. The mean diameter and surface distribution were observed by Transmission Electron Microscopy (TEM; JEOL JEM-100CX, Japan). For TEM observations, the CSVC complex solution was properly diluted and dripped onto carbon-coated copper grid and then dried at room temperature.

\section{Preparation of different MWs of CS by exposure to $\gamma$-rays}

Different MWs of CS were prepared by exposure to $\gamma$-rays according to the previous reported method (El-Sawy et al., 2010). Briefly, CS was irradiated at different doses of 25, $50 \& 100 \mathrm{kGy}$ by 60Co $\gamma$-rays in solid form at dose rate of $3.52 \mathrm{kGy} / \mathrm{h}$ to prepare different MWs of CS and named as CS25, CS50 and CS100.

\section{Synthesis of CSVC complexes}

CSVC complexes were synthesized through the reaction between the amine groups of glucosamine units of different MW of CS backbone and VC. 
Briefly, certain amount of unirradiated CS (CS0), CS25, CS50 or CS100 was dissolved in $100 \mathrm{ml}$ containing $1 \%$ acetic acid then $\mathrm{VC}$ solution (the concentration of $\mathrm{VC}$ is equal to the concentration of glucosamine unit of CS) was added drop wise into CS solutions with stirring for $4 \mathrm{~h}$. The product was precipitated by acetone, filtered, washed with acetone again to remove unreacted compounds, and then dried to obtain different types of CSVC complexes according to the value of CS irradiated dose; CS0VC, CS25VC, CS50VC and CS100VC.

\section{Determination of scavenging activity (\%)}

Measurement of scavenging activity (\%) on DPPH radicals was determined according to the method described previously (Yamaguchi et al., 1998). Briefly, $1.5 \mathrm{ml}$ of DPPH solution (0.1 mM, in $95 \%$ ethanol) was incubated with $1.0 \mathrm{ml}$ of different concentrations of CSVC complex solutions. The reaction mixture was shaken well and incubated for $15 \mathrm{~min}$ at room temperature and the absorbance of the resulting solution was read at $517 \mathrm{~nm}$ against a blank. Ascorbic acid was used for comparison as antioxidant materials. The scavenging activity (\%) was measured as a decrease in the absorbance of DPPH and can be calculated using the following equation:

Scavenging activity $(\%)=\left[1-\left(\mathrm{A}_{\text {samples } 517 \mathrm{~nm}} / \mathrm{A}_{\text {control } 517 \mathrm{~nm}}\right)\right] \mathrm{x} 100$

\section{Determination of reducing power}

The reducing power was determined by the method described by (Yen and Duh, 1993). Briefly, $1.0 \mathrm{ml}$ of different concentrations of CSVC complex solutions was mixed with $2.5 \mathrm{ml}$ of $0.2 \mathrm{M}$ sodium phosphate buffer $\mathrm{pH} 6.6$ and $2.5 \mathrm{ml}$ of $1 \%(\mathrm{w} / \mathrm{v})$ potassium ferricyanide. The mixtures were incubated for $20 \mathrm{~min}$ at $50{ }^{\circ} \mathrm{C}$. The reaction was terminated by adding $2.5 \mathrm{ml}$ of $10 \%$ TCA to the mixtures, followed by centrifugation for 10min at speed of $1500 \mathrm{rpm} .2 .5 \mathrm{ml}$ supernatant was mixed with $2.5 \mathrm{ml}$ distilled water and $0.5 \mathrm{ml}$ ferric chloride $(0.1 \%)$ solution and the absorbance was measured at $700 \mathrm{~nm}$. Increasing the absorbance of the reaction mixture indicates the increase in reducing power of the samples. Ascorbic acid was used for comparison as antioxidant materials.

\section{Preparation of dipping solutions for meat treatment}

Aqueous solutions of CS0, VC, CS0VC, CS25VC, CS50VC, and CS100VC were prepared at different concentrations of $0.05,0.1$ and $0.2 \%$ and stirred for 1-2h before using for dipping of meat.

Egypt. J. Rad. Sci. Applic., Vol. 27, No. 1-2 (2014) 


\section{Treatment of meat with CSVC mixtures and storage conditions}

Fresh meat was obtained from a local market and was ground using a blender. $10 \mathrm{~g}$ of ground sample were dipped on the prepared solutions for $10 \mathrm{~min}$. Samples without any dipping treatment was used as control. The treated meats were then gently drained on a tissue paper, placed in polyethylene bags and stored in the refrigerator at $4^{\circ} \mathrm{C}$ for 7,15 and 21 days. Each treatment contained three replicates and the experiment was repeated three times.

\section{Assessment of lipid oxidation of meat}

Lipid oxidation was assessed according to the TBARS assay (Vynche, 1970) and on the basis of the concentration of MDA formed during 0,7,15 and 21 days of refrigerated storage $\left(4^{\circ} \mathrm{C}\right)$. Triplicate $10 \mathrm{~g}$ samples (for each group) were homogenized with $50 \mathrm{ml}$ of $7.5 \%$ TCA solution. The homogenate was filtered and $5.0 \mathrm{ml}$ aliquot was transferred to a clean screw capped tube and mixed with $5.0 \mathrm{ml}$ of freshly prepared $0.02 \mathrm{M}$ TBA solution. The mixture was put in a boiling water bath for $35 \mathrm{~min}$ until colour formation, and then it was left to cool. The absorbance of the developed pink colour was measured at wavelength $532 \mathrm{~nm}$ against blank. MDA is one of the aldehydes formed during lipid oxidation in the meat and was expressed as $\mathrm{mg} \mathrm{MDA} / \mathrm{kg}$ sample.

The decrease $(\%)$ in MDA/kg at storage time $($ day $)=\left[\left(\mathrm{Abs}_{\mathrm{at} 532 \mathrm{~nm}}\right.\right.$ of treated samples - $\mathrm{Abs}_{\text {at } 532 \mathrm{~nm}}$ of control samples)/ $\mathrm{Abs}_{\text {at } 532 \mathrm{~nm}}$ of control samples]x 100 .

\section{Data analysis}

An average value of the replicate analyses was used in calculations of sample variation and significance testing. All statistical analysis was performed with SPSS (SPSS Inc., USA). Values are presented as means.

\section{Results and Discussion Synthesis and characterization of CSVC complexes}

The formation of CSVC complex was carried out by ionic interaction between amino groups of CS and the acidic hydroxyl group at carbon 3 of VC. FT-IR spectra of CS (Fig. 1, curve a) shows basic characteristic absorption bands at $3440 \mathrm{~cm}^{-1}$ (O-H and N-H stretch), $1651 \mathrm{~cm}^{-1}$ corresponding to the stretching of amide $\mathrm{C}=\mathrm{O}, 1598 \mathrm{~cm}^{-1}$ (N-H bend), $1387 \mathrm{~cm}^{-1}$ (Amide), $1154 \mathrm{~cm}^{-1}$ (asymmetric bridge-O-stretch) and $1089 \mathrm{~cm}^{-1}$ (skeletal vibration involving the 
C-O stretch). FT-IR of irradiated CS was reported in our previous paper (Abd El-Rehim et al., 2012), it was found there is no significant change between FTIR of unirradiated and irradiated CS indicating that the stability of the $\beta$ glycosidic bonds and distribution of glycosidic bonds in the molecular chains of CS. FT-IR spectra of VC (Fig. 1, curve b) shows four peaks at 3527, 3413, 3317 and $3217 \mathrm{~cm}^{-1}$ were attributed to the four $-\mathrm{OH}$ groups at $\mathrm{C}(6)-\mathrm{OH}, \mathrm{C}(3)-\mathrm{OH}$, $\mathrm{C}(5)-\mathrm{OH}$ and $\mathrm{C}(2)-\mathrm{OH}$, respectively. The bands at 1754 and $1673 \mathrm{~cm}^{-1}$ are corresponding to lactone $\mathrm{C}=\mathrm{O}$ and $\mathrm{C}=\mathrm{C}$ stretching, respectively. The $\mathrm{C}-\mathrm{H}$ stretching is assigned at $3029-2920 \mathrm{~cm}^{-1}$ (Lohmann et al., 1984). The bands at 1386 and $1260 \mathrm{~cm}^{-1}$ are due to C-O stretching vibration.

FT-IR spectrum of CSOVC (Fig. 1, curve c) shows that the bands at 3440 and $1598 \mathrm{~cm}^{-1}$ characteristic of $\mathrm{NH}_{2}$ bending vibrations gradually weakened and a new absorption band appeared at $1757 \mathrm{~cm}^{-1}$ due to $\mathrm{C}=\mathrm{O}$ group of ascorbic acid. These results suggest that the $\mathrm{NH}_{2}$ groups in the $\mathrm{CS}$ chains were protonated by the $\mathrm{H}^{+}$supplied by ascorbic acid (Zheng et al., 2008). The FT-IR spectra of CS25VC, CS50VC and CS100VC (Fig. 1, curves d, e and f) show a decrease in peak intensity at $3440 \mathrm{~cm}^{-1}$ indicated the reduction of free $-\mathrm{NH}_{2}$ groups after the formation of CSVC mixtures. This is due to radiation degradation of $\mathrm{CS}$ lead to decrease inter- and/or intra-molecular hydrogen bonding between the $-\mathrm{OH}$ and $-\mathrm{NH}_{2}$ groups resulting in increasing carbonyl groups formation at $1749 \mathrm{~cm}^{-1}$ and to increase the amount of functional groups formed such as $-\mathrm{OH}$ groups and so the intensity of the band at $3340 \mathrm{~cm}^{-1}$ corresponding to $-\mathrm{OH}$ and $-\mathrm{NH}_{2}$ groups. The vibrational band at $1100 \mathrm{~cm}^{-1}$ that corresponds to the ether bond in the pyranose ring has no significant change during the reaction with VC. Fig. 2A shows the MW of CSVC complex decreases with decreasing the starting MW of CS. The MW of CS at $0,25,50$ and $100 \mathrm{kGy}$ was $1.9 \times 10^{6}, 7.8 \times 10^{5}, 3.1 \times 10^{5}$ and $9.7 \times 10^{4} \mathrm{Da}$, respectively. The MW of the obtained CSVC complexes was $1.68 \times 10^{5}, 1.1 \times 10^{5}, 7.3 \times 10^{4}$ and 4.6 $\mathrm{x} 10^{4} \mathrm{Da}$, respectively. Fig. $2 \mathrm{~B}$ shows UV spectra of VC exhibits a strong absorption band at about $265 \mathrm{~nm}$ which is due to the л-л* excitation of the $\mathrm{C}(2)=\mathrm{C}(3)$ double bond. UV spectra of CS shows absorption band around 280$315 \mathrm{~nm}$ which may be caused by the $\mathrm{n} \rightarrow \sigma^{*}$ transition for the amino groups of $\mathrm{CS}$ and may also assigned to the $\mathrm{n} \rightarrow \pi^{*}$ transition for the carbonyl groups. UV spectra of CSVC complex show a strong absorption band at $265 \mathrm{~nm}$ and its intensity increases with decreasing the MW of starting CS.

Egypt. J. Rad. Sci. Applic., Vol. 27, No. 1-2 (2014) 


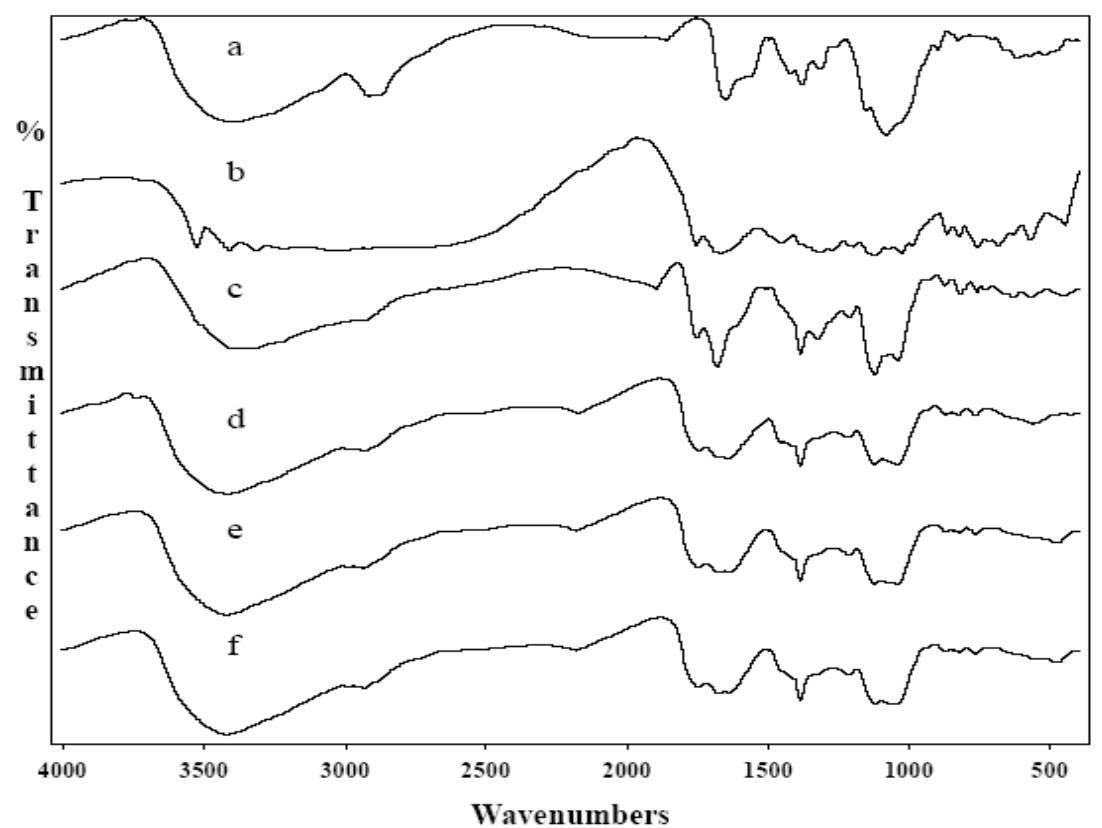

Fig. 1. FT-IR spectra of (a) CS, (b) VC, (c) CSOVC, (d) CS25VC, (e) CS50VC and (f) CS100VC.
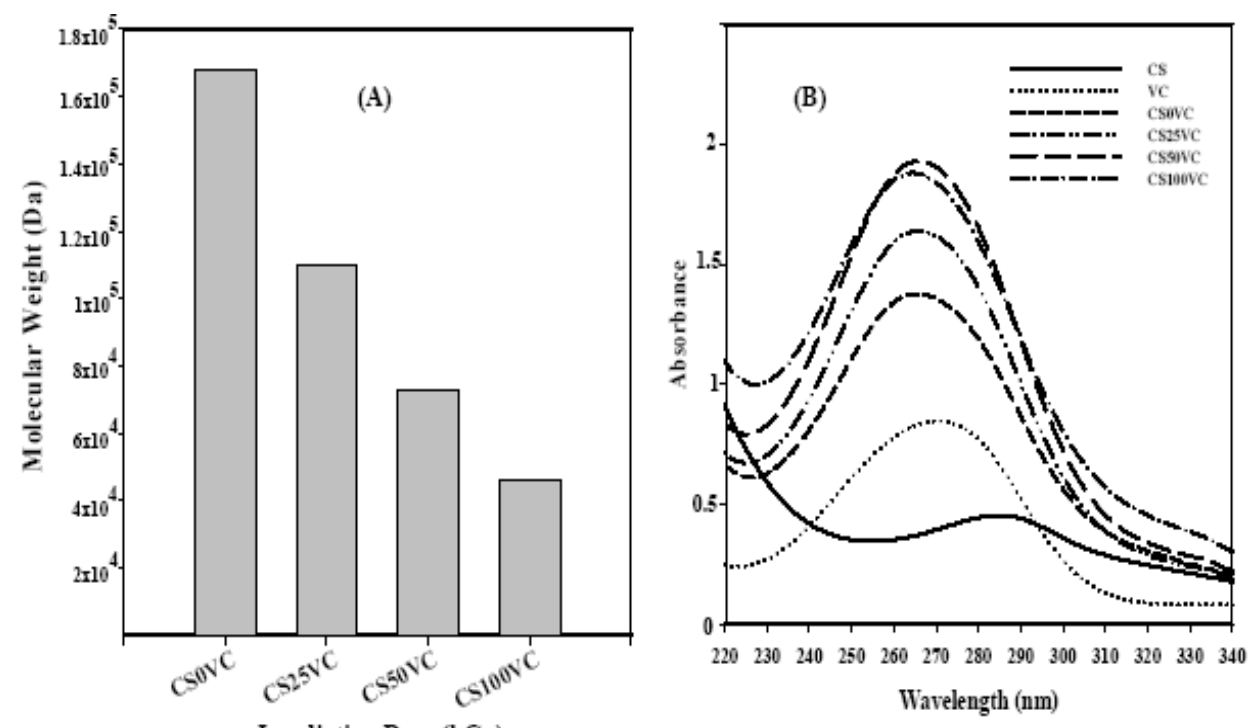

Fig. 2. (A) The Mw of CSVC complexes measured by GPC technique. (B) UV spectra of CS, VC and CSVC complexes.

Egypt. J. Rad. Sci. Applic., Vol. 27, No. 1-2 (2014) 
Fig. 3 shows the morphology of (a) CS50VC and (b) CS100VC complexes analyzed by TEM. The CSVC complex show a dark, solid and consistent structure resulted in aggregated with diameters ranged from 23.2 to $82 \mathrm{~nm}$. These CS50VC mixtures possessed a mean particle size of 82, 52.6, 46.5, 40 and $23.2 \mathrm{~nm}$. Also, CS100VC complexes possessed a mean particle size of 55.4, $48.3,42.1,41.137 .2,31.5$ and $28.2 \mathrm{~nm}$. It was found that particle sized of CSVC complex was controlled by decreasing the MW of starting CS.

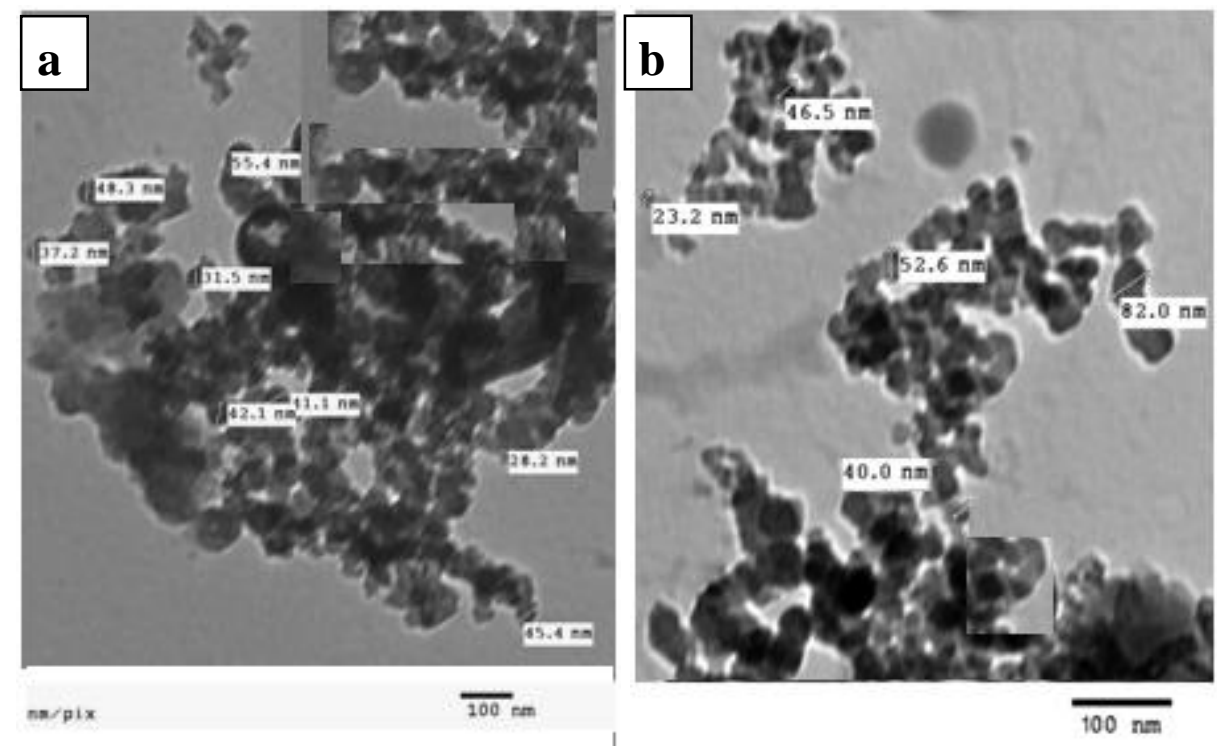

Fig. 3. TEM images of (a) CS50VC and (b) CS100VC.

\section{Scavenging Activity (\%)}

Antioxidant properties, especially radical scavenging activities, are very important due to the deleterious role of free radicals in foods and in biological system (Pan et al., 2008). Fig. 4. shows the scavenging activity (\%) of unirradiated CS, irradiated CS, VC and different types of CSVC complexes on DPPH radicals. Generally, the scavenging activity (\%) on DPPH increases with increasing the concentration. The scavenging activity (\%) of CS was enhanced by $\gamma$-irradiation. The lower MW of CS, the higher scavenging activity. At $70 \mu \mathrm{g} / \mathrm{ml}$ concentration, the scavenging activity (\%) of CS irradiated at $0,25,50$ and $100 \mathrm{kGy}$ was 3, 14.5, 19.8 and $28.5 \%$, respectively if compared with that of $\mathrm{VC}(42 \%)$. This is due to the high MW of CS which has compact structure,

Egypt. J. Rad. Sci. Applic., Vol. 27, No. 1-2 (2014) 
thus making the overall effect of their intra-molecular hydrogen bonds stronger lead to decrease the reactivity of hydroxyl and amino groups. On the contrary, low MW CS has a less compact structure, thus making the overall effect of intra-molecular hydrogen bonding less effective and so increase the reactivity of hydroxyl and amino groups.

Incorporation of CS molecules with VC had a synergistic effect on increasing the scavenging activity (\%) on DPPH rather than their individual effects. The CSVC complexes with lower MW of CS have a promising effect on increasing the scavenging activity. The CS100VC had the highest scavenging activity on DPPH. At the concentration $70 \mu \mathrm{g} / \mathrm{ml}$, the scavenging activity (\%) on DPPH of CS0VC, CS25VC, CS50VC and CS100VC was 49.2, $72.5,81.3$ and $91.5 \%$, respectively. Percentage of inhibition $\mathrm{IC}_{50} \%$ is used very frequently as parameters characterizing the antioxidant power. $\mathrm{IC}_{50}$ of CS25VC, CS50VC and CS100VC was 32, 22.5 and $18 \mu \mathrm{g} / \mathrm{ml}$, respectively. These results revealed that the prepared CSVC complexes have a good antioxidant activity.

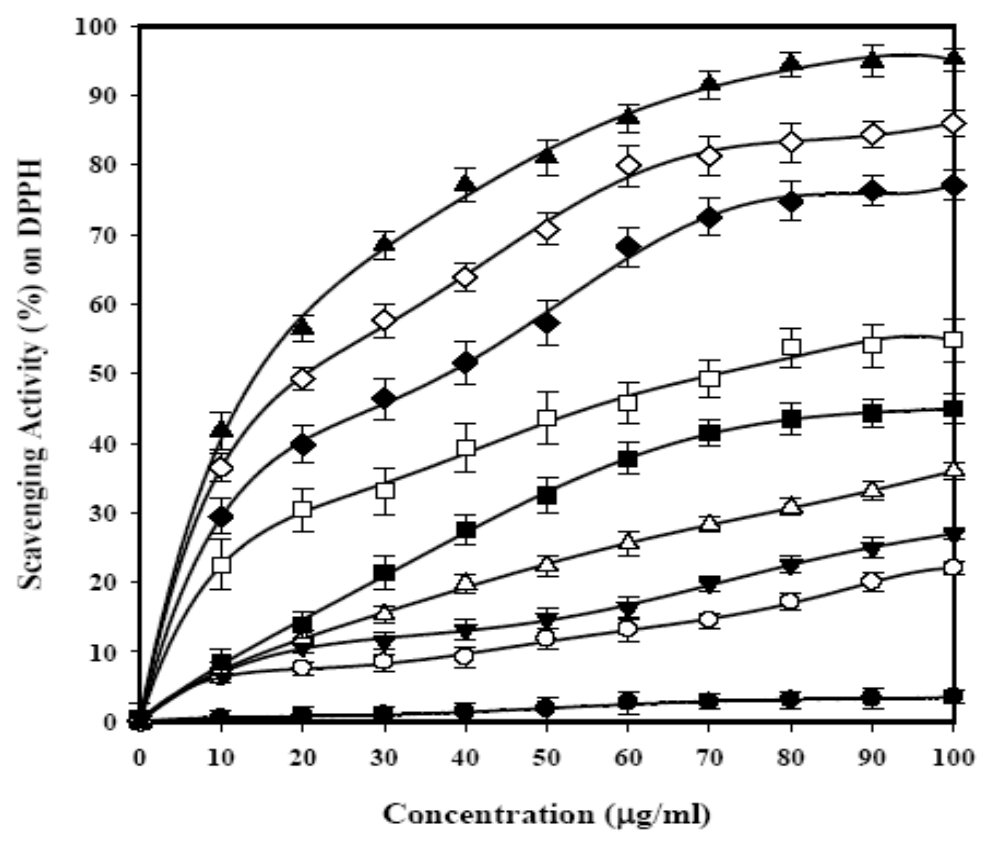

Fig. 4. Scavenging activity (\%) on DPPH radicals of $(\bullet)$ CS, $(\circ)$ CS25, ( $)$ CS50, $(\Delta)$

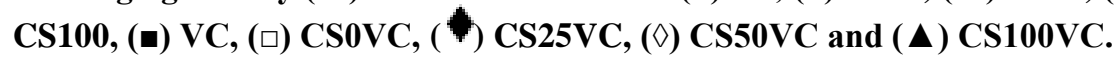

Egypt. J. Rad. Sci. Applic., Vol. 27, No. 1-2 (2014) 


\section{Reducing power}

Antioxidant activity has been reported to be concomitant with reducing power. Fig. 5. shows the reducing power of unirradiated CS, irradiated CS, VC and different types of CSVC complexes. CSVC complexes with low Mw CS showed high reducing power and the reducing power increases with increasing the concentration. The reducing power reach its maximum value at $1.0 \mathrm{mg} / \mathrm{ml}$ concentration then levelled off with further increase in concentration.

At $1.0 \mathrm{mg} / \mathrm{ml}$ concentration, the reducing power of CS0, CS25, CS50, CS100, VC, CS0VC, CS25VC, CS50VC and CS100VC was 0.3225, 0.495, $0.69,0.8809,1.3503,1.2314,2.582,2.813$ and 2.8877 , respectively. Increasing the absorbance indicates increasing reducing power activity. CS50VC and CS100VC complexes showed high reducing properties compared to CS or VC. The increase in reducing power of CSVC complexes indicates the enhancement of their antioxidant activity suggesting their possible use as antioxidants for preventing flavour changes caused by lipid peroxidation.

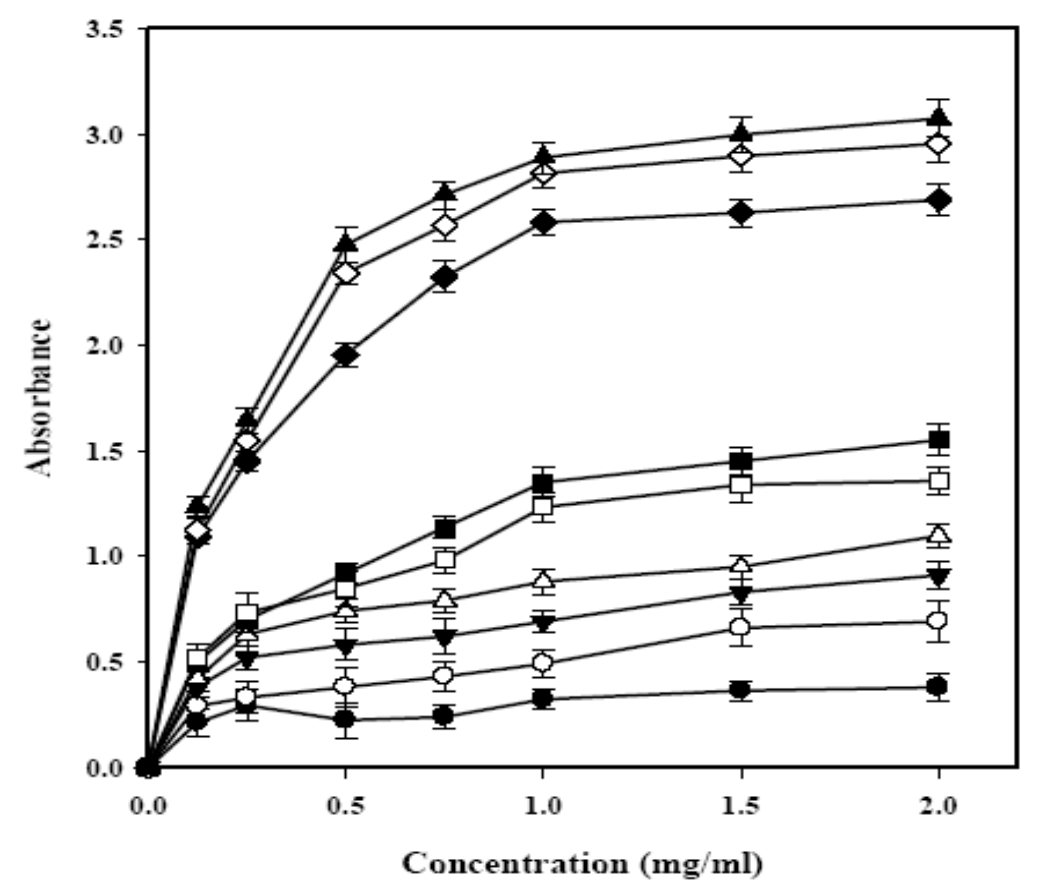

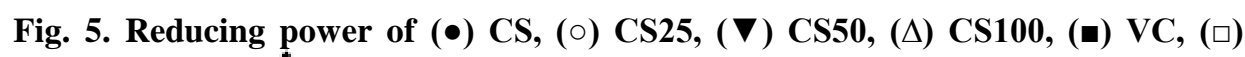
CSOVC, $(\bullet)$ CS25VC, $(\diamond)$ CS50VC and $(\Delta)$ CS100VC.

Egypt. J. Rad. Sci. Applic., Vol. 27, No. 1-2 (2014) 


\section{Lipid oxidation of meat during storage}

During storage of meat, lipid peroxides are formed with a subsequent formation of peroxyl radicals, followed by a decomposition phase to yield aldehydes such as MDA (Shahidi, 1994). MDA is an equivalency for stating TBARS values as mg MDA/kg of meat. Table 1. presented TBARS values for treated and untreated meat.

In the present study, control samples (untreated) had the MDA of 0.5042, 0.7481 and $0.955 \mathrm{mg} / \mathrm{kg}$ at 7,15 and 21 days of storage respectively, and would therefore be perceived as rancid already after the 15 days of storage. Whereas TBARS values for meat treated samples were decreased until the end of the storage period. TBARS values changes accordingly to storage period, the type and concentration of the additive. The treatment of meat using CSVC complexes during storage lead to decrease MDA values indicating the decrease in rate of lipid oxidation of meat. The MDA concentration of meat samples treated by CS or VC reached 0.8442 and $0.6823 \mathrm{mg} / \mathrm{kg}$ at 21 days and $0.2 \%$ concentration, respectively. Meanwhile, the effectiveness of CSOVC on MDA concentration was $0.5671 \mathrm{mg} / \mathrm{kg}$ with a decrease about 32.8-16.8 \% in MDA concentration. The incorporation of $\mathrm{CS}$ with $\mathrm{VC}$ solution improves the protection of the meat samples against lipid oxidation as a decrease in MDA concentration. In comparison with the control and groups of meat treated by CS or VC, TBARS values of CS25VC, CS50VC and CS100VC showed good effect on delaying peroxidation of meat by extending the induction period as results of their antioxidant properties. However, the TBARS value of the CS100VC treated group was higher than the CS25VC and CS50VC treated samples owing to the decrease in MW of CS.

From Table 1, using CS100VC complex at $0.05 \%$ concentration and storage time of 7, 15 and 21 days, the decrease (\%) in MDA/kg of meat was 55 , 39 and $40.7 \%$, respectively. While, at $0.1 \%$ concentration the decrease $(\%)$ in MDA $/ \mathrm{kg}$ was 67,43 and $45 \%$, respectively, and at $0.2 \%$ concentration the decrease $(\%)$ was 75,46 , and $50 \%$, respectively.

After storage time of 7, 15 and 21 days, the decrease (\%) in MDA/kg of treated meat at $0.05 \%$ concentration was $3,5.3$ and $9.8 \%$, respectively for using CS and was 17.5, 21 and $23.5 \%$ for using VC. While, at $0.2 \%$ 
concentration the decrease (\%) was $7.5,8.3$, and $11.6 \%$, for using CS and was $19.6,21,28.5 \%$, respectively for using VC. The increase in the properties and activities of CSVC complex promote their possible use as antioxidant and a food additive for delaying lipid peroxidation.

TABLE 1. Values of TBARS value of treated meat during 7, 15 and 21 days of storage at $4 \pm 1^{\circ} \mathrm{C}$ using different concentration of different treatments of CS, VC, CSOVC, CS25VC, CS50VC and CS100VC.

\begin{tabular}{|c|c|c|c|c|c|c|c|c|c|}
\hline Storage & \multicolumn{3}{|c|}{7 days } & \multicolumn{3}{|c|}{15 days } & \multicolumn{3}{|c|}{21 days } \\
\hline $\begin{array}{l}\text { Conc. } \\
\text { Type }\end{array}$ & $0.05 \%$ & $0.1 \%$ & $0.2 \%$ & $0.05 \%$ & $0.1 \%$ & $0.2 \%$ & $0.05 \%$ & $0.1 \%$ & $0.2 \%$ \\
\hline Control & - & $\underset{\mathrm{a}}{0.5042}$ & - & - & $\begin{array}{c}0.7481 \\
\mathrm{a}\end{array}$ & - & - & $\underset{\mathrm{a}}{0.955}$ & - \\
\hline CS & $\underset{\mathrm{b}}{0.4888}$ & $\underset{\mathrm{b}}{0.4884}$ & $\begin{array}{c}0.466 \\
\mathrm{~b}\end{array}$ & $\underset{\mathrm{b}}{0.6953}$ & $\begin{array}{c}0.6494 \\
\mathrm{~b}\end{array}$ & $\underset{b}{0.6354}$ & $\begin{array}{c}0.8613 \\
b\end{array}$ & $\underset{\mathrm{b}}{0.851}$ & $\begin{array}{c}0.8442 \\
\mathrm{~b}\end{array}$ \\
\hline VC & $\underset{\mathrm{c}}{0.416}$ & $\begin{array}{c}0.4006 \\
\mathrm{c}\end{array}$ & $\underset{c}{0.405}$ & $\underset{\mathrm{c}}{0.6162}$ & $\underset{\mathrm{c}}{0.6003}$ & $\underset{\mathrm{c}}{0.5902}$ & $\begin{array}{c}0.73 \\
\mathrm{c}\end{array}$ & $\underset{c}{0.7205}$ & $\begin{array}{c}0.6823 \\
\text { bc }\end{array}$ \\
\hline CSOVC & $\underset{\mathrm{d}}{0.3782}$ & 0.3544 & $\begin{array}{c}0.3374 \\
\mathrm{~d}\end{array}$ & $\underset{\mathrm{d}}{0.5623}$ & $\begin{array}{c}0.5494 \\
\mathrm{~d}\end{array}$ & $\underset{\text { cd }}{0.5315}$ & $\underset{\mathrm{d}}{0.6182}$ & $\underset{\mathrm{d}}{0.5838}$ & $\begin{array}{c}0.5671 \\
\text { cd }\end{array}$ \\
\hline CS25VC & $\underset{\mathrm{e}}{0.3396}$ & $\underset{\mathrm{e}}{0.3051}$ & $\underset{\mathrm{e}}{0.2957}$ & $\underset{\mathrm{e}}{0.5157}$ & $\underset{\mathrm{e}}{0.5015}$ & $\underset{\mathrm{de}}{0.4957}$ & $\underset{\mathrm{e}}{0.6059}$ & $\underset{\mathrm{e}}{0.5808}$ & $\underset{\mathrm{d}}{0.525}$ \\
\hline CS50VC & $\underset{\mathrm{f}}{0.2913}$ & 0.2248 & $\underset{\mathrm{f}}{0.2147}$ & $\underset{\mathrm{f}}{0.4911}$ & $\underset{\mathrm{f}}{0.4832}$ & $\begin{array}{c}0.469 \\
2^{\mathrm{f}}\end{array}$ & 0.5776 & 0.5752 & $\underset{\mathrm{d}}{0.4955}$ \\
\hline $\begin{array}{c}\text { CS100V } \\
\text { C }\end{array}$ & $\underset{\mathrm{g}}{0.2233}$ & $\underset{\mathrm{g}}{0.1663}$ & $\underset{\mathrm{g}}{0.1259}$ & $\underset{\mathrm{g}}{0.4567}$ & $\underset{\mathrm{g}}{0.4249}$ & $\underset{f}{0.4036}$ & $\underset{\mathrm{g}}{0.566}$ & $\underset{\mathrm{g}}{0.5247}$ & 0.4761 \\
\hline LSD & 0.0058 & 0.0015 & 0.0055 & 0.0015 & 0.0038 & 0.0039 & 0.0013 & 0.0015 & 0.138 \\
\hline
\end{tabular}

\section{Conclusion}

CSVC complexes were synthesized in the range of nanoparticles through the ionic interaction of $\mathrm{VC}$ with $\mathrm{CS}$ molecules of different MW prepared by exposure to $\gamma$-rays. CSVC complexes had a synergistic effect on increasing the scavenging activity (\%) on DPPH and high reducing power rather than their individual effects. The treatment of meat by CSVC complexes resulted in a highly significant decrease (\%) in MDA/kg after 7 days of storage about $75 \%$. CS50VC and CS100VC complexes showed high decrease (\%) in MDA $/ \mathrm{kg}$ of minced meat. It can be concluded that CSVC complexes could be used as antioxidants and a food additives for lipid storage.

\section{Acknowledgment}

The authors express deep gratitude and thanks to Dr. Dalia Zahran, Health Radiation Research Dept., NCRRT, for her cooperation in the biological site.

Egypt. J. Rad. Sci. Applic., Vol. 27, No. 1-2 (2014) 


\section{References}

Abd El-Rehim, H. A., El-Sawy, N. M., Hegazy, E. A., Soliman, E. A. and Elbarbary, A. M. (2012) Improvement of antioxidant activity of chitosan by chemical treatment and ionizing radiation. Int. J. Biol. Macromol., 50, 403.

Anraku, M., Kabashima, M., Namura, H., Maruyama, T., Otagiri, M. and Gebicki, J. M. (2008) Antioxidant protection of human serum albumin by chitosan. Int. J. Biol. Macromol., 43, 159.

El-Sawy, N. M., Abd El-Rehim, H. A., Elbarbary, A. M. and Hegazy, E. A. (2010) Radiation-induced degradation of chitosan for possible use as a growth promoter in agricultural purposes. Carbohyd. Polym., 79, 555.

Georgantelis, D., Blekas, G., Katikou, P., Ambrosiadis, I. and Fletouris, J. (2007) Effect of rosemary extract, chitosan and $\alpha$-tocopherol on lipid oxidation and color stability during frozen storage of beef burgers. Meat Sci., 75, 256.

Ilyina, A. V., Tikhonov, V. E., Albulov, A. I. and Varlamov, V. P. (2000) Enzymic preparation of acid free water soluble chitosan. Process Biochem., 35, 563.

Jeon, Y. J. and Kim, S. K. (2001) Potential immuno-stimulating effect of antitumoral fraction of chitosan-oligosaccharides. J. Chitin Chitosan, 6, 163.

Li, X., Shi, X., Jin, Y., Ding, F. and Du, Y. (2013) Controllable antioxidative xylanchitosan Maillard reaction products used for lipid food storage. Carbohyd. Poly., 91, 428.

Lohmann, W., Pagel, D. and Penka, V. (1984) Structure of ascorbic acid and its biological function determination of the conformation of ascorbic acid and isoascorbic acid by infrared and ultraviolet investigations. Eur. J. Biochem., 138, 479.

Ma, Z., Yang, L., Yan, H., Kennedy, J. F. and Meng, X. (2013) Chitosan and oligochitosan enhance the resistance of peach fruit to brown rot. Carbohyd. Polym., 94, 272.

Nissen, L. R., Byrne, D. V., Bertelsen,G. and Skibsted, L. H. (2004) The antioxidative activity of plant extracts in cooked pork patties as evaluated by descriptive sensory profiling and chemical analysis. Meat Sci., 68, 485.

Pan, Y., Wang, K., Huang, S., Wang, H., Mu, X. and He, C. (2008) Antioxidant activity of microwave-assisted extract of longan (Dimocarpus Longan Lour.) peel. Food Chem., 106, 1264.

Park, P. J., Je, J. Y., Byun, H. G., Moon, S. H. and Kim, S. K. (2004) Antimicrobial activity of hetero-chitosans and their oligosaccharides with different molecular weights. J. Mol. Microbiol. Biotechnol., 14, 317.

Porporatto, C., Bianco, I. D., Riera, C. M. and Correa, S. G. (2003) Chitosan induces different $\mathrm{L}$-arginine metabolic pathways in resting and inflammatory macrophages. Biochem. Biophys. Res. Commun., 304, 266. 
Rao, M. S., Chander, R. and Sharma, A. (2005) Development of shelf stable intermediate moisture meat products using active edible chitosan coating and irradiation. J. Food Sci., 70, 325.

Sayas-Barberá, E., Quesada, J., Sánchez-Zapata, E., Viuda-Martos, M., Fernández-López, F., Pérez-Alvarez, J. A. and Sendra, E. (2011) Effect of the molecular weight and concentration of chitosan in pork model burgers. Meat Sci., 88, 740.

Shahidi, F. (1994) Assessment of lipid oxidation and off-flavor development in meat and meat products. In F. Shahidi (Ed.), Flavor of meat and meat products. Blackie Academic and Professional., New York, pp. 247-266.

Soultos, N., Tzikas, Z., Abrahim, A., Georgantelis, D. and Ambrosiadis, I. (2008) Chitosan effects on quality properties of Greek style fresh pork sausages. Meat Sci., 80, 1150.

Suman, S. P., Mancini, R. A., Joseph, P., Ramanathan, R., Konda, M. K., Dady, G. and Yin, S. (2011) Chitosan inhibits premature browning in ground beef. Meat Sci., 88, 512.

Sun, T., Zhu, Y., Xie, J. and Yin, X. (2011) Antioxidant activity of N-acyl chitosan oligosaccharide with same substituting degree. Bioorg. Med. Chem. Lett., 21, 798.

Suzuki, K., Mikami, T., Okawa, Y., Tokoro, T., Suzuki, S. and Suzuki, M. (1986) Antitumor effect of hexa-N-acetylchitohexaose and chitohexaose. Carbohyd. Polym., 151, 403.

Vyncke, W. C. (1970) Direct determination of the thiobarbituric acid extract of fish as a mean of oxidative rancidity. Fette Seifen Anstrichmittel., 72, 1084.

Yamaguchi, T., Takamura, H., Matoba, T. and Terao, J. (1998) HPLC Method for Evaluation of the Free Radical-scavenging Activity of Foods by Using 1,1diphenyl-2-picrylhydrazyl. Biosci. Biotechnol. Biochem., 62, 1201.

Yen, G. C. and Duh, P. D. (1993) Antioxidative properties of methanolic extracts from peanut hulls. J. Am. Oil Chem. Soc., 70, 383.

Yen, M. T., Yang, J. H. and Mau, J. L. (2008) Physicochemical characterization of chitin and chitosan from crab shells. Carbohyd. Polym., 75, 15.

Ying, G. Q., Xiong, W. Y., Wang, H., Sun, Y. and Liu, H. Z. (2011) Preparation, water solubility and antioxidant activity of branched-chain chitosan derivatives. Carbohyd. Polym., 83, 1787.

Zheng, C., Yan, X., Si, J. G., Meng, Y., Qi, Z. and Tao, Z. (2008) Ionic interactions between sulfuric acid and CS membranes. Carbohyd. Polym., 73, 111.

(Received: 14/08/2014;

accepted: $30 / 09 / 2014)$

Egypt. J. Rad. Sci. Applic., Vol. 27, No. 1-2 (2014) 


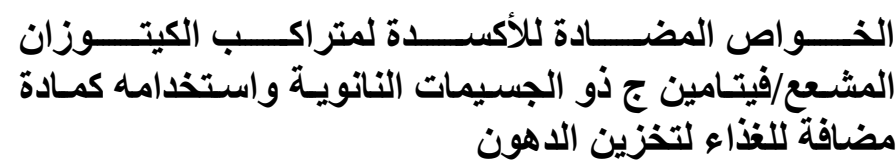

أحمد محمد البربري ، و نعيم محمد الصاوي ، و السيد أحمد عبدالعزيز حجازي

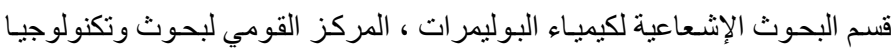

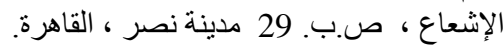

تم تحسين النشاطية المضادة للاككسدة للكيتوز ان عن طريق تقليل وزنـهـ

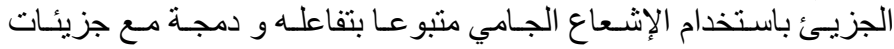

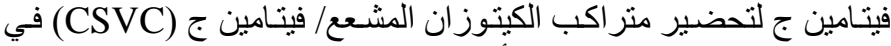

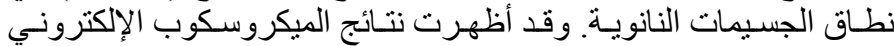

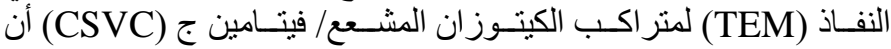

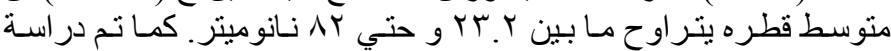

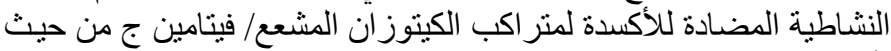

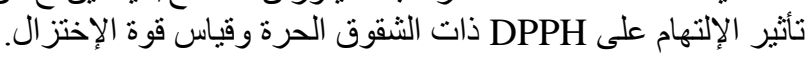

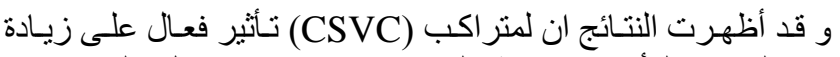

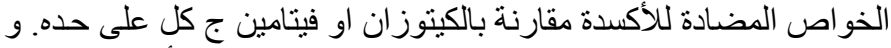

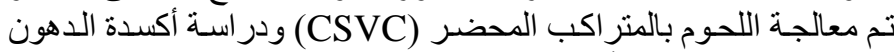

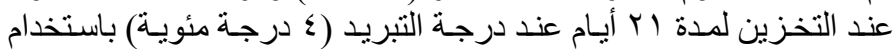

اختبار حامض الثيوباربتيوريك (TBARS test) و التعبير عنها بتركيز

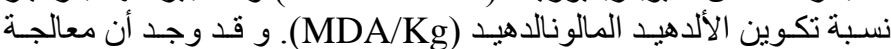

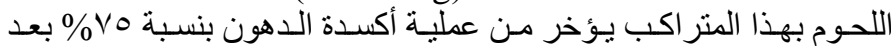

تخزين اللحوم لمدة V أيام عند درجة التبريد.

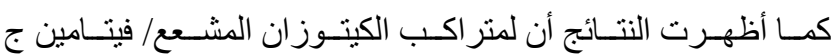

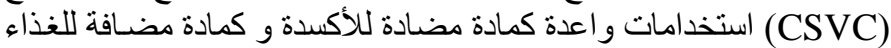

ل التقليل أكسدة الدهون أثناء التخزين.

Egypt. J. Rad. Sci. Applic., Vol. 27, No. 1-2 (2014) 